\title{
The clumping of Staphylococcus pyogenes by serum and fibrinogen-free plasmas
}

\author{
A. E. BROWN AND A. A. FARUQUE \\ From the Department of Pathology, General Hospital, West Hartlepool, Co. Durham
}

SYNOPSIS Fifty strains of Staphylococcus pyogenes were tested for 'coagulase' by the slide method using plasma, serum, and plasmas rendered fibrinogen-free by various methods. It was found that the organisms were clumped by all these reagents. The significance of these findings is discussed.

Much (1908) first observed the clumping of Staphylococcus aureus by human plasma. This phenomenon was found to parallel the clotting of plasma by Staphylococcus aureus and was developed by BirschHirschfeld (1934) and Cadness-Graves, Williams, Harper, and Miles (1943) into a rapid test for 'coagulase'. Duthie (1954) brought evidence to show that the slide coagulase test depends upon a 'clumping factor' attached to the cell. In his view this clumping factor acts directly upon 'susceptible' fibrinogen and alters it so that it precipitates upon the surface of the organisms causing them to clump.

It was found in this laboratory that a serum caused the clumping of a strain of Staphylococcus pyogenes and it was decided to investigate whether this reaction could be repeated using other strains of Staphylococcus pyogenes with other sera and with plasma rendered fibrinogen-free by several accepted methods.

\section{MATERIALS AND METHODS}

The oxalated plasma used for all reagents was obtained by pooling blood specimens received daily for urea estimation.

REAGENTS The reagents were prepared as follows:-

1 Oxalated plasma was diluted 1 in 10 with physiological saline. To $10 \mathrm{ml}$. of diluted plasma was added $1 \mathrm{ml}$. of $2.5 \%$ calcium chloride solution. The tube was incubated at $37^{\circ} \mathrm{C}$. for four to six hours and then the clot was removed. The remaining fluid was centrifuged and the supernatant used as reagent.

2 One millilitre of human thrombin solution (50 N.I.H. units) was added to $2.5 \mathrm{ml}$. of the 1 in 10 plasma. The tube was incubated at $37^{\circ} \mathrm{C}$. for four to six hours and the clot removed. The remaining fluid was centrifuged and the supernatant used as reagent.

3 Undiluted plasma, $0.2 \mathrm{ml}$., was added to $3.8 \mathrm{ml}$. of $12.5 \%$ sodium sulphite solution. The mixture was shaken and allowed to stand for $10 \mathrm{~min}$., then shaken again and centrifuged. The supernatant was used as reagent.

Received for publication 25 February 1963
4 Normal blood, $10 \mathrm{ml}$., was taken into a $1 \mathrm{oz}$. bottle containing three glass beads and the bottle inverted gently until clotting took place. The blood was then incubated at $37^{\circ} \mathrm{C}$. overnight to allow full clot retraction. The bottle was centrifuged and the serum separated.

Calcium chloride, thrombin, and sodium sulphite solutions were all tested to see if they caused clumping of Staphylococcus pyogenes. None did so.

Fifty unselected strains of Staphylococcus pyogenes and six strains of Staphylococcus albus were tested.

A smooth heavy suspension of the organisms was made in a loopful of distilled water on a clean grease-free slide. (Distilled water is used routinely in this laboratory in preference to saline because it has been found that autoagglutination occurs much less frequently.) One loopful of reagent was placed beside the suspension and stirred into it for 10 to 15 seconds. The mixture was then examined for macroscopic clumping of the organisms. Each strain was tested with oxalated plasma, calcium chloride-treated plasma, thrombin-treated plasma, sodium sulphite-treated plasma, and serum.

One of the strains of Staphylococcus pyogenes taken at random was tested with 25 unselected sera received in the laboratory for various biochemical tests.

\section{RESULTS}

Table I shows the results obtained with the various reagents tested against the 50 strains of Staphylococcus pyogenes.

Table II shows the results obtained with the six strains of Staphylococcus albus.

The single strain tested against a range of sera gave positive results with 20 sera and doubtful results with five sera. Those sera giving doubtful results with this strain were tested against another strain and gave positive results.

Reactions described as positive gave clear-cut clumping at 15 seconds. Those described as doubtful gave weak but recognizable clumping within two minutes. 
TABLE I

\begin{tabular}{|c|c|c|c|c|c|}
\hline RESI & WITH VARIOUS & REAGENTS AGAINST & STAPH. PYOGENES & & \\
\hline Reagent & Oxalated Plasma & $\begin{array}{l}\text { Calcium-treated } \\
\text { Plasma }\end{array}$ & $\begin{array}{l}\text { Thrombin-treated } \\
\text { Plasma }\end{array}$ & $\begin{array}{l}\text { Sulphite-treated } \\
\text { Plasma }\end{array}$ & Serum \\
\hline No. of strains giving positive result & 50 & 50 & 49 & 33 & 44 \\
\hline No. of strains giving doubtful result & 0 & 0 & 1 & 12 & 4 \\
\hline No. of strains giving negative result & 0 & 0 & 0 & 5 & 2 \\
\hline
\end{tabular}

TABLE II

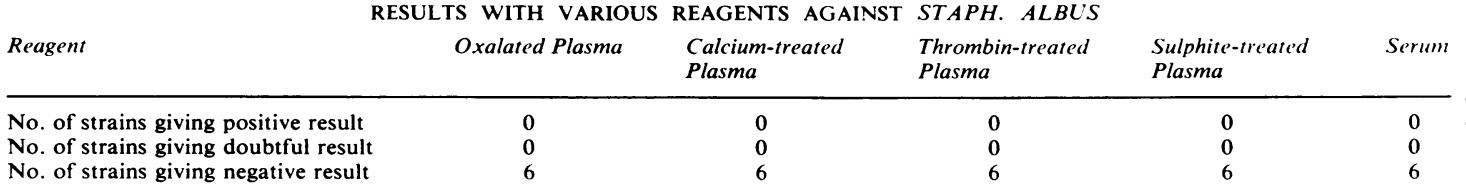

Two of the sera used were heavily inoculated with a strain of Staphylococcus pyogenes and incubated for $24 \mathrm{hr}$. at $37^{\circ} \mathrm{C}$. The organisms were then separated by centrifugation and the supernatant retested for clumping reaction. It had retained the power to clump strains of Staphylococcus pyogenes, including the one with which it had been inoculated.

\section{DISCUSSION}

The results obtained do not support the theory that the action of the clumping factor is dependent upon the presence of fibrinogen; therefore this factor cannot be described as a coagulase.

Other workers who have reported clumping with fibrinogen-free solutions are Lack and Wailling (1954) who obtained clumping of staphylococci with some mouse sera and also found that the addition of human serum to mouse plasma enhanced the slide coagulase response of this plasma, and Birsch-Hirschfeld (1934) who obtained clumping with her crude prothrombin solution which had been rendered fibrinogen-free. Duthie (1954), in putting forward his theory for the action of 'bound' coagulase, noted the results of Birsch-Hirschfeld but claimed that the finding was due to the presence of traces of denatured fibrinogen.

In our tests several methods of removing fibrinogen were used to rule out the possibility that traces of fibrinogen were present, and precautions were taken to ensure complete clotting of the normal blood samples used. One serum was also subjected to electrophoresis and showed no sign of a fibrinogen band. It seems difficult therefore to believe that if a minute quantity of fibrinogen did remain it could have given the clear-cut clumping obtained.

A possible explanation of our results would be the presence of a naturally occurring agglutinin against the staphylococci. The fact that all 25 unselected sera gave clumping is against this, as is the fact that the degree of clumping was not reduced by absorption of the serum with a heavy suspension of Staphylo- if coccus pyogenes.

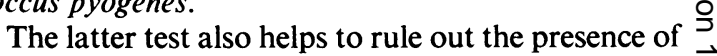
small traces of fibrinogen which should have been os removed on the surface of the deposited organisms.

On the other hand many workers have used 'purified' fibrinogen solutions to test for the clumping factor and plasma does give a slight but definitely better clumping than serum.

We ourselves have obtained good clumping of staphylococci by redissolving the precipitate obtained when preparing sodium sulphite-treated plasma and using this as a reagent.

\section{CONCLUSIONS}

The action of a clumping factor is not dependent upon the presence of fibrinogen though clumping is enhanced when fibrinogen is present. If an accessory factor is necessary, it may be found in both the precipitates and the supernatant fluids obtained in the various salting out methods of producing 'pure'? fibrinogen solutions. A theory which would fit these two conclusions is that an accessory factor is necessary and that some proportion of this factor is removed in the process of clotting or salting out of fibrinogen. It is possible that this accessory factor is a 음 protein which does not clot, resembling fibrinogen $\rightarrow$ and similar to that described by Tillett and Garner (1934) as causing clumping of streptococci.

We would like to thank Dr. H. McTaggart for his com- $N$ ments on this paper and Dr. R. T. Cooke for permission to publish it.

\section{REFERENCES}

Birsch-Hirschfeld, L. (1934). Klin. Wschr., 13, 331.

Cadness-Graves, B., Williams, R., Harper, G. J., and Miles, A. A. (1943). Lancet, 1, 736.

Duthie, E. S. (1954). J. gen. Microbiol., 10, 427.

Lack, C. H., and Wailling, D. G. (1954). J. Path. Bact., 68, 431.

Much, H. (1908). Biochem. Z., 14, 143.

Tillett, W. S., and Garner, R. L. (1934). Bull. Johns Hopk. Hosp., 54, 用 145. 